\title{
Representaciones bibliotecarias sobre la biblioteca pública, la lec- tura, el lector, la promoción y la animación a la lectura en Medellín, Colombia
}

\author{
Didier Álvarez Zapata * \\ Yicel Nayrobis Giraldo Giraldo * \\ Norfi Yamili Ocampo Molina ** \\ Luz Marina Guerra Sierra ** \\ Liliana Melgar Estrada *** \\ Maricela Gómez Vargas *
}

Artículo recibido:

10 de marzo de 2009.

Artículo aceptado:

3 de diciembre de 2009.

\section{RESUMEN}

El artículo aborda las representaciones bibliotecarias sobre la biblioteca pública, la lectura, el lector, la promoción y la animación a la lectura que tienen los directores y promotores de lectura de las bibliotecas públicas de la ciudad de Medellín.

Palabras clave: Biblioteca pública / Promoción de la lectura / Animación a la lectura / Lectura / Lector / Medellín

* Universidad de Antioquia, Colombia. (Didier: dial@bibliotecología.udea.edu.co); (Yicel: yicel@bibliotecologia.udea.edu.co); (Maricela: maricegova@gmail.com).

** Fundación Ratón de Biblioteca, Colombia. (Yamili: yamiliocampo.m@gmail.com); (Luz: lumage@gmail.com)

*** Investigadora independiente, Colombia. lilimelgar@gmail.com

INVESTIGACIÓN BIBLIOTECOLÓGICA, Vol. 23, Núm. 49, septiembre/diciembre, 2009, México, ISSN: 0187-358X. pp. 197-240 
Library representations about the Public library, reading, the reader, and promotion and encouragement to reading in Medellin, Colombia

Didier Álvarez Zapata; Yicel Nayrobis Giraldo Giraldo; Norfi Yamili Ocampo Molina; Luz Marina Guerra Sierra; Liliana Melgar Estrada and Maricela Gómez Vargas

Library representations about Public library, reading, the reader, and promotion and encouragement to reading maintained by reading directors and promoters in the public libraries of the city of Medellin, are approached.

Keywords: Public library; Reading promotion; Reading encouragement; Reading: Reader; Medellin.

\section{INTRODUCCIÓN}

Es: ste artículo presenta una mirada a las representaciones bibliotecarias de la biblioteca pública, la lectura, los lectores, la promoción y la animación a la lectura que se tienen en Medellín. En él se entiende por representaciones bibliotecarias a todos aquellos conocimientos particulares sobre la institución bibliotecaria y sus prácticas sociales, técnicas y administrativas; así como a las dimensiones culturales en las que desarrolla la biblioteca su acción social, específicamente en las esferas simbólicas de la lectura, la escritura y la información. Se asume, además, que estas representaciones son elaboradas (difundidas y apropiadas) por las comunidades de práctica bibliotecaria, con el fin de hacer inteligible, explicable y comprensible ante la sociedad y otras comunidades su ser y hacer en el sistema social. Así pues, las representaciones bibliotecarias determinan las iniciativas que desarrollan las bibliotecas en la comunidad.

El trabajo es producto de la investigación titulada Exploración de los discursos y las prácticas de la promoción de la lectura en las bibliotecas públicas de Medellín: una revisión del lugar social de la biblioteca pública en la formación de los lectores, realizada por el Equipo de Investigación en Biblioteca Pública y Lectura, del Grupo de Investigación en Biblioteca Pública — GIBP— de la Escuela Interamericana de Bibliotecología de la Universidad de Antioquia, 
en asociación con la Fundación Ratón de Biblioteca. Esta investigación se propuso mostrar el estado de las principales categorías institucionales y organizacionales de la biblioteca pública que condicionan el desarrollo de las iniciativas de promoción de la lectura.

El artículo desarrolla, inicialmente, los conceptos fundamentales que soportaron el trabajo de investigación partiendo del reconocimiento del lenguaje, la cultura y el discurso como elementos estructurales de los procesos de construcción social del conocimiento. Este continúa con una breve alusión a los aportes que este campo hace a los estudios sobre la biblioteca como institución social y de la lectura. Seguidamente, se presentan algunas consideraciones metodológicas básicas para abordar los contenidos de las representaciones bibliotecarias de la biblioteca pública, la lectura, los lectores, la promoción y la animación a la lectura que se tienen en Medellín; para terminar con el planteamiento de algunas conclusiones.

\section{LAS REPRESENTACIONES SOCIALES}

Y LA INVESTIGACIÓN DE LA BIBLIOTECA

\section{El lenguaje y la cultura}

La cultura es el ámbito de significaciones, representaciones y sentidos que les permite a los hombres estar y vivir en el mundo social. El mundo es una representación posible por la acción mediadora del lenguaje, y éste es la llave de acceso al universo de significados disponibles. La cultura le da sentido a la existencia del hombre, no sólo en términos objetivos y simbólicos, sino porque además le concede referentes del orden transcendental. Es por ello que Mélich le otorga a la cultura un lugar preponderante para la comprensión de la sociedad, pues la cultura, como parte del mundo social, es, en términos de Geertz "esa urdimbre, ese conjunto de enlaces que constituyen el horizonte de significado a partir del cual nos movemos y existimos". ${ }^{1}$

Si bien la cultura permite el acceso a los universos simbólicos, al lenguaje, a los modos de significado y de interpretación, en fin, al mundo de la vida, no pueden, sin embargo, perderse de vista las relaciones de la cultura con el sistema, con los usos del poder que se legitiman por la circulación social de selectos contenidos simbólicos. Aquí vale la pena detenerse en la compresión de las relaciones entre la cultura, específicamente del lenguaje, como vehículo de acceso al entramado de significados sociales; y del sistema, como ámbito de realización 
del poder y, por lo tanto, de la aceptación de la dominación de unos (los dominantes) sobre otros (los dominados). En esta línea, Téllez Iregui, comentador de la obra de Bourdieu, dice que

el mundo social (...) superando la oposición entre realidad y representación, se construye también a partir de procesos simbólicos que implican lenguaje y otras formas representativas. La realidad exterior es objeto de percepciones y representaciones mentales; por ello, hay que incluir esas formas de conocimiento como parte de la realidad, pues también son objeto de las luchas sociales. ${ }^{2}$

En forma similar, H. Giroux, discípulo de Freire, establece una íntima relación entre lenguaje y poder, puesto que el lenguaje, tal y como él lo definiera

desempeña un rol activo en la construcción de la experiencia y en la organización y legitimación de las prácticas sociales disponibles para los diversos grupos existentes en la sociedad. ${ }^{3}$

El lenguaje es el insumo de la cultura y constituye, a bien decir de Gramsci, un terreno de dominación como un campo de posibilidad:

el lenguaje es al mismo tiempo hegemónico y contrahegemónico, y resulta un instrumento válido tanto para silenciar la voz de los oprimidos, como para legitimar relaciones sociales de opresión. ${ }^{4}$

En todo ello se puede constatar que el lenguaje es, a la vez, bien cultural monopolizado, como también instrumento para imponer la legitimidad de los arbitrarios culturales, en forma de símbolos. Así pues,

el acceso al lenguaje legítimo —el dominante— es desigual. El lenguaje legítimo es monopolizado por unos pocos. Hay monopolio sobre el mercado de los bienes lingüísticos (capital cultural) como lo hay sobre el mercado de los bienes económicos. $^{5}$

2 Gustavo Téllez Iregui, Pierre Bourdieu. Conceptos básicos y construcción socioeducativa: Claves para su lectura, Bogotá: Universidad Pedagógica Nacional, 2002, p. 84.

3 Henry Giroux, "Introducción: La alfabetización y la pedagogía de la habilitación política”, en Alfabetización: Paulo Freire y Donaldo Macedo, Lectura de la palabra y lectura de la realidad, Barcelona: Paidós, 1989. p. 32.

$200 \quad 5$ Téllez Iregui, op. cit., p. 121. 
El lenguaje está lejos de ser un territorio libre de la lucha cultural, el lenguaje, más bien, encarna la confrontación por la posesión de los bienes simbólicos para naturalizar relaciones sociales desiguales y excluyentes.

\section{El discurso como parte del proceso de construcción social de la realidad}

El lenguaje se materializa como hecho mediante el discurso, como manifestación concreta de la capacidad simbólica del hombre a través de la escritura o del habla. El discurso hace parte de lo que se dice de la realidad, de la percepción de los fenómenos que son captados por los sentidos, los cuales son traducidos y fijados por las palabras y las imágenes. Por ello el discurso es lenguaje, y este último, a su vez, es manifestación y sustentación del universo simbólico, portador de maneras concretas de ver el mundo, la sociedad, el hombre y el sistema. El discurso media en la adquisición de las herramientas culturales para el despliegue de estrategias que le permitan al hombre actuar, pensar, sentir y vivir en el mundo social.

$\mathrm{Al}$ vincular de este modo lenguaje y discurso, adquiere sentido la afirmación de Ricoeur en la que dice que "sólo el hombre tiene un mundo y no simplemente una situación". ${ }^{6} \mathrm{El}$ hombre, mediante el concurso del lenguaje hecho discurso, se libera de la visibilidad y limitación de las situaciones, al abrirse al mundo, es decir, dándole nuevas dimensiones a ese ser-en-el-mundo. En este sentido, Heidegger, retomado por Ricoeur, afirmaba que lo que entendemos primero en un discurso no es a otra persona sino un proyecto, es decir, el esbozo de un nuevo ser-en-el-mundo. ${ }^{7}$

Así pues, el discurso es sistema, fenómeno y acontecimiento comunicativo de carácter social. Como se sigue a continuación, se presentan estas tres definiciones de discurso, las cuales provienen de campos teóricos diversos pero con significativas conexiones:

En primer lugar, definimos el discurso como manifestación concreta del lenguaje, de la manera como se ve, percibe, interpreta e interviene la realidad social en la ecuación de mundo de la vida y el sistema. El discurso es la expresión y el despliegue del universo simbólico, entendido como el conjunto de esquemas de significado socialmente objetivado que se refiere, por un lado, al mundo de la vida cotidiana, y por otro lado a un mundo que se experimenta como trascendente. ${ }^{8}$ Así pues, el universo simbólico determina y define las actuaciones y mediaciones lingüísticas y culturales entre los sujetos

6 Paul Ricoeur, "El modelo del texto : La acción significativa considerada como un texto", en Del texto a la acción. Ensayos de Hermenéutica II, [s.1] : [s.n], 1986, p. 174.

7 Ibid., p. 174.

8 Ibid., p. 41. 
y los objetos en diversos contextos sociales. El lenguaje y, consecuentemente, el discurso son ordenadores de este universo simbólico, perpetuadores de la estructura simbólica, del edificio cultural del cual hacen parte —y harán parte - los sujetos y las instituciones. El lenguaje permite integrarse a ese orden preestablecido, preexistente a los sujetos: "cuando nacen tiene ya preparado, para cada uno, su lugar en el conjunto de las relaciones sociales"9.

Desde la perspectiva de la teoría comunicacional, el discurso puede concebirse simultáneamente como fenómeno (está ahí) y como acontecimiento comunicativo (ocurre en el tiempo y en el espacio). En primera instancia, en el discurso intervienen: el emisor, quien produce la comunicación; el receptor, a quien va dirigida la comunicación; el discurso, como el mensaje o contenido de la comunicación; el contexto social que determina la producción y recepción del contenido del mensaje; el canal, como el medio físico de comunicación entre el emisor y el receptor o destinatario del mensaje.

La tradición hermenéutica, por su parte, define el discurso como acontecimiento en forma de lenguaje. En este sentido, establece cuatro rasgos para caracterizar al discurso:

1) el discurso se realiza siempre temporalmente y en un presente;

2) el discurso remite a quien lo pronuncia a un conjunto complejo de referentes;

3) el discurso es siempre acerca de algo, se refiere a un mundo que pretende describir, expresar o representar; y

4) el discurso tiene, no únicamente un mundo, sino otro, un interlocutor al cual está dirigido. La puesta en escena de este conjunto de rasgos permite afirmar que el discurso ocurre en el tiempo y en el espacio, con la participación de un productor, que se refiere a algo, y que espera establecer la relación con un interlocutor.

Además, también se entiende el discurso como sistema. Para validar esta idea, se recurre a la definición de sistema propuesta por Puleo, como "un conjunto de entidades caracterizadas por ciertos atributos, que tienen relaciones entre sí y están localizadas en un cierto ambiente, de acuerdo con un cierto objetivo". ${ }^{10}$ Así, se puede decir que por discurso se entenderá el conjunto de elementos-entidades (sujetos, contenidos) que establecen relaciones entre

9 Jesús Ibáñez, "Los avatares del sujeto", en Nuevos avances en la investigación social. Suplemento Anthropos, Núm. 22 (1990), citado por Joan Carles Melich, Antropología simbólica y acción educativa, Barcelona: Paidós, 1996. p. 45. trónico], http://members.tripod.com/ gepsea/sistema.htm , [consulta: 12 oct. 2005]. 
sí y están determinadas por los ambientes sociales y organizacionales (entorno organizacional — contexto social - contexto profesional) de diversa magnitud y alcance. Adicionalmente, el discurso a su vez como producto, depende de la acción y puesta en marcha de procesos de producción, circulación y recepción en los diferentes niveles organizacionales y sociales, los cuales están determinados por normas, mediaciones y posibilidades que regulan tal realización.

\section{Las representaciones sociales}

Las representaciones sociales se sitúan en el punto intermedio en donde se intersectan lo psicológico y lo social. Para el primero, las representaciones sociales integran la participación activa de un sujeto cognoscente, dotado de condiciones biológicas y psicológicas, para apropiarse cognitivamente (en tanto procesos y estructuras) del mundo social del que hace parte. Por ello, las representaciones sociales conciernen

a la manera cómo nosotros, sujetos sociales, aprehendemos los acontecimientos de la vida diaria, las características de nuestro medio ambiente, las informaciones que en él circulan, a las personas de nuestro entorno próximo o lejano (Jodelet, 1988: 473).

Para el segundo, las representaciones sociales son una forma de conocimiento social que circula en el cúmulo de las interacciones cotidianas de seres humanos que tienen lugar por el lenguaje, las cuales orientan las acciones y determinan el comportamiento social de los individuos. Por lo tanto, las representaciones sociales son "una manera de interpretar y de pensar nuestra realidad cotidiana, una forma de conocimiento social". ${ }^{11}$ Además, son sociales porque se modelan en la interacción entre los sujetos que construyen permanentemente sus mundos de vida. ${ }^{12}$

Antes bien, valdría la pena mencionar que la génesis del concepto de representación social se remonta al concepto de representaciones colectivas acuñado por el sociólogo francés Emile Durkheim para referirse, en oposición a las representaciones individuales, a todas aquellas ideas compartidas homogéneamente por todos los miembros de una sociedad. Su propósito era subrayar la importancia y preeminencia que la sociedad tiene sobre el individuo. En

11 Denise Jodelet, "La representación social: fenómenos, concepto y teoría", en Serge Moscovici, Psicología social. Pensamiento y vida social II, Barcelona: Paidós, 1988, p. 473.

12 María A. Banchs, Álvaro Agudo Guevara y Lislie Astorga, "Imaginarios, representaciones y memoria social”, en Ángela Arruda, y Martha De Alba, coords., Espacios imaginarios y representaciones sociales. Aportes desde Latinoamérica, Barcelona: Anthropos; México: UAm Iztapalapa, División Ciencias Sociales y Humanidades, 2007, p.69. 
palabras de Moscovici, para referirse a las representaciones colectivas afirma que:

Son colectivas en la medida en que están encarnadas en la comunidad donde son compartidas homogéneamente por todos sus miembros. Son comunales, además, porque han sido compartidas por varias generaciones de individuos y ejercen sobre ellos una coerción [... ] ya sea bajo la apariencia de religiones, mitos o lenguajes, ejercen una influencia sobre los individuos y refuerzan de una manera uniforme sus lazos recíprocos. Las representaciones son entonces equiparadas a la colectividad, en esta concepción hay una representación singular relacionada con un grupo en el cual ninguna otra representación prevalece. ${ }^{13}$

De modo particular, Moscovici con la publicación de su trabajo La psychanalyse: son image et son public en 1961, recupera el concepto de representaciones colectivas de Durkheim y sugiere entonces un giro en el modo de comprensión de las relaciones entre el sujeto y el objeto de conocimiento, así como en la base misma de la comprensión del conocimiento social y de sentido común. En esta línea, Moscovici aporta importantes elementos a la sociología del conocimiento de la que se venían ocupando teóricos como Berger y Luckmann al decir que

[...] una "sociología del conocimiento" deberá tratar no sólo las variaciones empíricas del "conocimiento" en las sociedades humanas, sino también los procesos por los que cualquier cuerpo de "conocimiento" llega a quedar establecido socialmente como "realidad" [...] sostenemos que la sociología del conocimiento se ocupa del análisis de la construcción social de la realidad. ${ }^{14}$

Sin duda, dicho trabajo marcó el inicio de un importante campo de estudio, el de las representaciones sociales en la psicología social. En este trabajo, Moscovici subraya que Durkheim disoció los hechos sociales de la conciencia individual, a la representación colectiva de la representación individual, ya que las "totalidades sociales son concebidas como indivisibles, por presentar rasgos emergentes irreductibles a sus elementos individuales". ${ }^{15}$ En este sentido, las explicaciones sociales de la sociedad como un todo se imponen a los individuos como una serie de propiedades que les son exteriores. De hecho,

13 Serge Moscovici, Psicología social. Pensamiento y vida social II, Barcelona: Paidós, 1988.

14 Peter L. Berger y Thomas Luckmann, La construcción social de la realidad, Argentina: Amorrortu, 2001; p. 15.

15 José Antonio Castorina, Alicia Barreiro y Fernando Clemente, "La impronta del pensamiento piagetano en la teoría de las representaciones sociales", en Revista IRICE, Rosario, Argentina, Núm. 18, (Sep. 2004). 
el mismo Piaget reconoce las limitaciones originarias en el pensamiento de Durkheim respecto de la escisión entre el sujeto epistémico y el objeto de conocimiento. En tal sentido afirma que la relación social constituye una totalidad en sí misma que produce nuevos caracteres que transforman al individuo en su estructura mental.

Así que la principal característica de las representaciones sociales es que, desde el punto de vista epistemológico, suponen un rechazo a la escisión clásica entre el sujeto y el objeto de conocimiento, originada en el pensamiento moderno y desarrollada por las teorías del conocimiento racionalista y empirista. De modo contrario, en las representaciones sociales no hay separación entre el "universo exterior y el universo interior del individuo. El sujeto y el objeto no son oscuramente distintos" (Moscovici, 1969: 9).

Igualmente, Moscovici también estuvo influenciado por las ideas de Lucien Lévy-Bruhl y su estudio sobre las funciones mentales en sociedades "primitivas", Jean Piaget y sus estudios sobre la representación del mundo en los y las niñas y las teorías de Sigmund Freud sobre la sexualidad infantil. Asimismo, Fritz Heider con sus estudios sobre psicología del sentido común y Peter Berger y Thomas Luckmann, con su propuesta de la construcción social del conocimiento. ${ }^{16}$ Igualmente, Moscovici afirma que tuvo en cuenta los trabajos de Lev Vygotsky sobre el origen de las funciones mentales superiores y su estrecho vínculo con la historia social, por fuera del organismo individual, más allá de las profundidades de la mente y de los tejidos nerviosos.

Ahora bien, cuando nos referimos a las representaciones sociales, no podríamos dejar de lado las menciones que habrían de hacerse respecto de la definición fundamental del representar como un acto de pensamiento por medio del cual un sujeto se relaciona con un objeto mediante la asignación de una imagen (figura) a la que le atribuye un significado y un sentido. Representar, según el Diccionario de la Real Academia de la Lengua Española, es hacer presente algo con palabras o figuras que la imaginación retiene. En esta primera acepción encontramos los fundamentos de la representación como ejercicio mental - hacer presente en la mente, en la conciencia. En este sentido, la representación es la reproducción mental de una cosa: persona, objeto, acontecimiento, entre otros. Sin embargo, tal representación, como producto, es el resultado de la interacción que establece el sujeto con la sociedad y de los modos de apropiación particular que emprende en torno a los objetos de conocimiento que integra a su estructura, experiencia y vivencia. Por otra parte, representar también alude a sustituir a, estar en lugar de, hacer las veces

16 Sandra Araya Umaña, Las representaciones sociales: ejes teóricos para su discusión, Costa Rica: FLACSO, 2002, 84 p., [documento electrónico], disponible en: <http://www.flacso.or.cr/ fileadmin/documentos/FLACSO/Cuaderno127.pdf>, [consultado: 26 de junio de 2008]. 
$d e$. En esta línea, la representación es el representante mental de algo: objeto, persona, acontecimiento o idea.

Los elementos que integran la representación son, a juicio de Jodelet, ${ }^{17}$ aquellos que tienen que ver con el contenido y con el sujeto portador de la representación. Del primero debe decirse que alude al conjunto de informaciones, opiniones y actitudes relacionadas con el objeto representado. Del segundo, esto es del sujeto (en tanto individuo, familia, grupo o clase), concibe a la entidad humana productora y portadora del conjunto de informaciones, opiniones y actitudes asociadas a un objeto social. En consecuencia, debe decirse que toda representación lo es de algo y es de alguien. Sin duda, si ignoramos al sujeto en lo que concierne a las representaciones sociales:

[...] Nos quedamos frente a un conjunto de representaciones indiferenciadas que no hablan de la vida social. Las representaciones expresan identidades y afectos, intereses y proyectos diferenciados, refiriéndose así a la complejidad de las relaciones que definen la vida social. Entender su conexión fundamental con los modos de vida significa entender la identidad posible que un sistema de saberes asume en un momento histórico dado. Ahora bien, es solamente en relación con la alteridad, con los otros $[\ldots]$ que podremos entender y explicar esa identidad. ${ }^{18}$

Respecto del sujeto y su relación con el objeto, según Moscovici, la representación social,

a diferencia de otras formas de conocimiento, supone una relación específica entre el sujeto y el objeto de conocimiento: el individuo proyecta su identidad en el objeto que representa. ${ }^{19}$

El objeto no se construye totalmente por el concurso del objeto en sí mismo que se muestra al sujeto con interés de apropiarlo e integrarlo a su estructura, sin duda, el sujeto participa activamente del proceso de conocimiento del objeto, proyectándole parte de su identidad, afecto, emoción e intereses. Por lo tanto, la relación del sujeto con el objeto es completamente singular y particular, pues denota una forma específica de interacción de un sujeto en

17 Denise Jodelet, op. cit.

18 Sandra Jovchelovitch, Psicologia social, saber, comunidade e cultura, [documento electrónico]. disponible en: <http://www.scielo.br/pdf/psoc/v16n2/a04v16n2.pdf>, [consultado: 14 de julio de 2008].

19 Moscovici Citado por C.Prado De Souza, Representaciones sociales y el imaginario de la escuela, en Ángela Arruda y M. De Alba, coords., Espacios imaginarios y representaciones sociales. Aportes desde Latinoamérica, Barcelona: Anthropos, México: UAM Iztapalapa, División Ciencias Sociales y Humanidades, 2007; p. 207. 
una situación y de un objeto en una posición. Sin embargo, en dicha relación también participan otros quienes intervienen en el proceso de construcción social del objeto mediante actos comunicativos que tienen lugar en la vida cotidiana.

Debe subrayarse, además, que las representaciones no son un reflejo de la realidad, "sino su estructuración significante, de modo tal que se convierten para los individuos en la "realidad misma" ${ }^{20}$ Las representaciones son producidas por alguien respecto de algo, un objeto de conocimiento, inmerso en un contexto social e histórico que los determina a ambos: al sujeto con el conjunto de sus situaciones, creencias, valores, intereses, posiciones y actuaciones; y al objeto y sus formas de expresión y manifestación. De suyo, las representaciones, como producciones, surgen en la interacción y en la comunicación social entre los sujetos, a la vez que son expresiones del sujeto respecto del lugar que ha construido en el mundo y de su posición en él. Por ello,

a la par que el individuo se constituye y constituye sus representaciones también constituye su mundo social y construye y reconstruye permanentemente su propia realidad social y su propia identidad personal..$^{21}$

De modo concreto, Moscovici define a las representaciones sociales como:

[...] una modalidad particular del conocimiento, cuya función es la elaboración de los comportamientos y la comunicación entre los individuos [...] La representación es un corpus organizado de conocimientos y una de las actividades psíquicas gracias a las cuales los hombres hacen inteligible la realidad física y social, se integran en un grupo o en una relación cotidiana de intercambios, liberan los poderes de su imaginación.

Por todo, las representaciones poseen un contenido mental concreto de un acto de pensamiento que restituye simbólicamente algo ausente, que aproxima algo lejano, ${ }^{22}$ Por consiguiente, la representación se caracteriza por:

20 José Antonio Castorina, Alicia Barreiro y Ana Gracia Toscano, "Dos versiones del sentido común: las teorías implícitas y las representaciones sociales", en José Antonio Castorina, comp., Construcción conceptual y representaciones sociales. El conocimiento de la sociedad, 2 ed. Buenos Aires: Miño y Dávila, 2007, p. 215.

21 Ángela Banchs, "Aproximaciones procesuales y estructurales al estudio de las representaciones sociales", en Papers on social representations, Vol. 9, (2000), p. 3.1 - 3.15, [documento electrónico], disponible en: <http://www.psr.jku.at/PSR2000/9_3Banch.pdf> , [consultado: 26 de junio de 2008].

22 Denise Jodelet, op. cit., p. 476. 
- Siempre es la representación de un objeto, no es el objeto en sí mismo, es la idea que se ha construido de él;

- Tiene carácter de imagen y la propiedad de poder intercambiar lo sensible y la idea, la percepción y el concepto;

- Tiene un carácter simbólico y significante; esto es, de sentido y de orientador de las acciones y los comportamientos;

- Tiene un carácter constructivo, esto es, de construcción de una idea, objeto o relación;

- Tiene un carácter autónomo y creativo, pues aunque la representación contiene un núcleo fuerte invariable, es posible su cambio. Castorina, Barreiro y Toscano plantean tres modos de producción y cambio de las representaciones sociales: ${ }^{23}$ a) a través de la divulgación de los avances científicos a la comunidad lega; b) a través de las prácticas sociales; y c) a través de las confrontaciones sociales entre los grupos sobre aspectos conflictivos de la vida social.

En la línea comprensiva de las representaciones como una forma de conocimiento social, se les atribuye un conjunto de características fundamentales relacionadas con la orientación de las acciones y de los comportamientos, en su sentido pragmático básico:

- Las representaciones son elaboraciones de grupos sociales que participan del interés socio-histórico de hacerlas coherentes como producción colectiva para asegurar la estabilidad del mundo y del lugar que particularmente el sujeto construye en él. Por lo tanto, las representaciones sociales son formas del conocimiento práctico contextualizado por medio de las cuales los sujetos orientan las acciones, producen y reproducen los marcos de interpretación y, por consiguiente, delimi$\tan$ las experiencias individuales y colectivas.

- Las representaciones sociales tienen un carácter implícito ya que los sujetos no tienen conciencia de su existencia, pues se trata de "producciones colectivas que al ser socialmente compartidas desbordan la conciencia individual, y en tal sentido decimos que son tácitas." 24 Por lo tanto, las representaciones, si bien son producciones colectivas, de las cuales también participa el sujeto respecto de su apropiación, proceden de manera tácita en la forma como el sujeto las integra a su experiencia cognitiva y social. 
- Las representaciones sociales conllevan una fuerte carga de "incuestionable realidad" del mundo social atado al interés de hacerlo comprensible desde unos ciertos lugares discursivos y desde unas ciertas maneras de ser, hablar, sentir y estar. Dicho con otras palabras, a las representaciones sociales se les atribuyen ciertas funciones en el marco de un mundo social que pretende hacerse comprensible y real para el conjunto de sus miembros, pues es por medio de ellas como se trata de configurar un conjunto de clasificaciones significativas que se producen y las cuales buscan "salvar" al mundo de las fisuras en la cultura o de conjurar aquel temor en la concepción griega del mundo de "horror al vacío". 25

\section{Importancia de estudiar este campo en el ámbito bibliotecario}

Debe mencionarse en el último tiempo, el interés que en el campo de los estudios bibliotecológicos sobre la lectura ha tenido el tema de las representaciones y prácticas sociales de la lectura, por no decir el tema del comportamiento social y la lectura. Más específicamente, cada vez toman mayor vigencia las relaciones entre lectura e información en aquello que, innegablemente, la compresión de las maneras en que las personas y los grupos sociales representan las prácticas del leer y el escribir se vuelven esenciales para poder darle respuestas a una bibliotecología que quiere interesarse más por su dimensión social y ayudar a construir vínculos sociales más incluyentes y humanizantes.

En este esfuerzo es importante resaltar las iniciativas que en algunos países de América Latina, para hablar desde nuestro ámbito regional, se vienen desarrollando. En este campo, pueden señalarse, corriendo el riesgo de dejar de mencionar otras experiencias valiosas, los trabajos de Elsa Ramírez Leyva y Margarita Castellanos Ribot en México, y Alejandro Parada en Argentina. También están los esfuerzos de la Asociación de Lectura de Brasil con su publicación Teoría y Práctica con investigadores tales como Luiz Percival Leme Brito, Marcia Abreu y Valdir Heitor Barzotto, entre otros. También debe mencionarse el esfuerzo del Grupo Fronesis por abordar y difundir las relaciones entre alfabetización y mundo político en cabeza de Rosa María Torres. Y recientemente los trabajos de la Línea de investigación en Biblioteca Pública y lectura de la Escuela Interamericana de Bibliotecología de la Universidad de Antioquia en Medellín. 


\section{Breve mención metodológica de lo que hizo la investigación}

La investigación en la cual se originó este artículo, abordó dos campos: el fáctico, para reconocer empíricamente las prácticas de promoción de la lectura, para lo cual se usaron herramientas de corte cuantitativo (encuestas); el formal para reconocer los discursos y las representaciones sobre la promoción de la lectura mediante la interrogación a través de documentos y entrevistas semiestructuradas.

La población de bibliotecas públicas integradas a la investigación fue de 11, de acuerdo con la tipología de biblioteca pública propuesta por el Grupo de Investigación en Biblioteca Pública de la Escuela Interamericana de Bibliotecología de la Universidad de Antioquia. ${ }^{26}$ Éstas son:

- Biblioteca pública del sector estatal

- Biblioteca pública del sector privado

- Biblioteca pública de iniciativa comunitaria-popular.

El sistema categorial que orientó el análisis de los discursos de las bibliotecas públicas estuvo integrado por los siguientes componentes:

\section{Contexto social}

Contexto configurado

(Bibliotecas Públicas)

PRÁCTICA Y

DISCURSO DE LA PROMOCIÓN DE LA LECTURA

Esencia

Enfoques

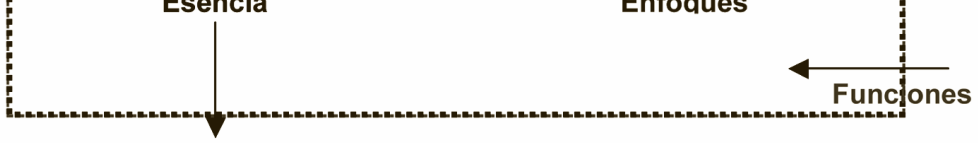

Finalidades

Ilustración 1: Categorías sociales que enmarcan el discurso y la práctica de la promoción de la lectura

26 Orlanda Jaramillo y Mónica Montoya, "Revisión del concepto de biblioteca pública”, en Revista Interamericana de Bibliotecología, Vol. 23, Núm. 1 - 2 (ene. - dic. 2000); pp. 13 - 56. 
- Por contexto social se entiende el conjunto de procesos sociales (culturales, educativos, políticos y económicos) que determinan las iniciativas.

- El contexto configurado se refiere a las miradas que las bibliotecas han construido y que les ayudan a entender el mundo social y político en el cual despliegan sus iniciativas de promoción de la lectura.

- Por función entendemos la tarea que le corresponde realizar a una institución o entidad, o a sus órganos o personas (DRAE). En nuestro caso se refiere a las demandas sociales expresas o tácitas que le hacen la sociedad y el Estado a la biblioteca pública en su calidad de institución social. En este sentido, construyen el orden bibliotecario.

- Por finalidad, entendemos el fin con el que o por el cual se hace algo (DRAE); esto se refiere a la traducción de las demandas sociales y estatales que hace la biblioteca al plantearle fines a sus prácticas. Dicho de otra manera, la finalidad se refiere a las intenciones que tienen las prácticas de promoción de la lectura.

- Por esencia del concepto se entiende la naturaleza en la cual descansa la intervención de la promoción de la lectura de la biblioteca pública.

- Por enfoque del concepto se entienden los aspectos de la promoción de la lectura en los cuales los conceptos hacen su énfasis o establecen su punto de mira respecto de la realidad o intervención en la realidad.

\section{LAS REPRESENTACIONES BIBLIOTECARIAS DE LA BIBLIOTECA PÚBLICA}

El concepto de biblioteca pública que tienen las bibliotecas públicas investigadas tiene como referente común al manifiesto UNESCO para la biblioteca pública, aunque el nivel de explicitación de ello en los discursos de los bibliotecarios sea muy variable. De hecho, las bibliotecas que más expresamente tienen propuesto su marco de referencia en el Manifiesto, son los sistemas bibliotecarios de Comfenalco y de la Biblioteca Pública Piloto, asunto éste comprensible en tanto que se reconoce su historia fuertemente atada a la promoción de estos ideales. Esto queda claro al ver, por ejemplo, los soportes de autoridad que principalmente convoca el texto escrito por los bibliotecólogos del Departamento de Cultura y Bibliotecas de Comfenalco, y la presentación de los libros que constituyen la colección Fomento de la Lectura: Informe de la Reunión de Caracas, y el mismo Manifiesto de 1994.

En el caso de las bibliotecas populares debe decirse que estos referentes prácticamente no aparecen y hasta se desconocen, puesto que circulan esencialmente entre bibliotecólogos con intereses en las bibliotecas públicas. 
No obstante llama la atención en todo esto que la idea de la biblioteca como espacio social se da por encima de un análisis sistemático de las prácticas culturales y políticas que se realizan en ella. Es como si la apropiación de la idea de que la biblioteca es socialmente útil siguiera dificultando develar la cotidianidad de ella misma.

De cualquier manera, en el discurso bibliotecario local son evidentes las alusiones a las funciones sociales de la biblioteca, por lo que se puede considerar que se la representa más como una institución. En este sentido, resulta interesante revisar las funciones que las instituciones estudiadas le asignan a la biblioteca pública. En esto debe recordarse lo ya propuesto anteriormente en este trabajo, lo que permite entender las funciones bibliotecarias como la respuesta que da la biblioteca a las demandas que desde la sociedad le llegan, pero también como el resultado de su propia iniciativa de acción social (sus finalidades) y la perspectiva del análisis que hace del contexto social. Los objetivos son, en esta medida, el punto de mira que la biblioteca pone para el cumplimiento de las funciones. De otra manera: las funciones son de corte filosófico mientras que los objetivos son de corte administrativo. En todo ello, desde luego, está de por medio la orientación ideológica (política, educativa, religiosa) que sustenta a cada biblioteca en su origen y que, de hecho, no se agota en la formulación amplia y universalista que plantea, por ejemplo, el Manifiesto UNESCO. La idea UNESCO de biblioteca, por cierto, uniforma la multiplicidad de la identidad de la biblioteca pública en una identidad globalizada. He ahí el problema de las tipologías de la biblioteca pública en Medellín: ¿una biblioteca vista en tres escenarios o se trata de tres bibliotecas ordenadas en una categoría que limita su muy variada identidad?

En particular puede decirse que las funciones substantivas de la biblioteca pública han empezado a considerarse en Medellín, principalmente, y como lo propone Comfenalco, dirigidas al cumplimiento de

(...) dos objetivos básicos: fomentar y promover la lectura, y posibilitar el libre acceso de las personas a la información local, regional e internacional, que dé cuenta del quehacer humano y de las diferentes culturas.

No obstante esta concepción con doble centro, que traza la acción institucional de Comfenalco desde la década de los años 90 (con la creación del Servicio de Información a la Comunidad en 1991; y de la Coordinación de Fomento de la Lectura en 1993), parece ser común a la mayoría de las bibliotecas pero sólo en lo pertinente a la promoción de la lectura, porque lo relacionado con la información local sigue estando muy lejos de la acción de las otras bibliotecas (grandes y pequeñas), salvo el caso de algunas bibliotecas populares 
que, con el apoyo de Comfenalco o por iniciativa propia, empiezan a tener pequeñas colecciones de información comunitaria. Sin duda, esta consideración orgánica de lectura e información local no logra calar con fuerza en el proyecto bibliotecario de la ciudad.

Así pues es posible decir que hay un acuerdo alrededor de la promoción de la lectura como una estrategia central de la biblioteca pública en Medellín. Lo dicen, por ejemplo, Comfenalco: "La BP busca: formar lectores críticos y autónomos e incrementar los niveles de lectura de la población”. La Biblioteca Pública Piloto al reconocer la prioridad de "prestar el servicio de promoción de la lectura”. La Fundación Ratón de Biblioteca cuando afirma que pretende “(...) generar una cultura de placer por la lectura [...] fomentando un reencuentro con los libros y el uso de la palabra afectuosa y con las formas simbólicas no violentas”. La Red de Bibliotecas Públicas de Medellín que propone que la biblioteca pública es una "institución para generar lectores". La Biblioteca Brisas del Norte que afirma que "la lectura es una actividad que debe ser incrementada a través de los estamentos gubernamentales educativos y, al mismo tiempo, por la biblioteca."

\section{Función social de la biblioteca pública}

Considerando ahora lo propuesto sobre las funciones sociales o de integración social de la biblioteca pública, puede decirse que gravitan alrededor de tres cosas:

- Que la biblioteca existe para contribuir a elevar, en general, el nivel de vida de las personas (despliegue de la vida íntima) y de las comunidades (despliegue de la vida colectiva) desde perspectivas, ya de estabilidad social: "[la biblioteca] es un espacio de encuentro y convocatoria de los distintos sectores de la comunidad" (Biblioteca PAN); o de progreso en el sentido clásico de este concepto:

La biblioteca pública es un puente para mejorar las condiciones de vida de las personas. La biblioteca pública puede ofrecer otras y mejores opciones de vida [...] hacer patria, hacer paz, hacer hermanad entre los seres humanos (Biblioteca Comfama).

La Fundación Ratón de Biblioteca:

en el Centro de Lectura, las organizaciones sociales han encontrado la posibilidad de conocer y de leer [...] es un lugar propicio para aprender, crear, generar intercambios y aperturas a nuevas ideas. 
(...) existe para trabajar por y con una sociedad a la que pertenece y, una de sus finalidades más comprometedoras, es que, de manera cooperativa, ayude a que las personas logren los fines de la vida, estos son: la superación personal, económica, intelectual (...)

- Que la biblioteca es un organismo que genera equilibrio social en el sentido de que ayuda a enfrentar la zozobra social en las comunidades. Buen ejemplo de ello es el trabajo de las bibliotecas populares, de Ratón de Biblioteca, de la Red de Bibliotecas Públicas de Medellín y de Comfenalco en sectores de conflicto social. Lo propone la Biblioteca Juan Zuleta Ferrer del sistema bibliotecario de la Biblioteca Pública Piloto:

[la biblioteca debe] ayudar a reconstruir la sociedad tan traumatizada [es necesario] plantear propuestas que hagan que la función de la biblioteca sea generadora de paz.

Pero lo dejan enteramente en claro las palabras de una de las promotoras de la lectura, al referirse al trabajo social que desarrolla la Biblioteca Centro Occidental de Comfenalco en el sector de la comuna 13 de Medellín:

[...] las organizaciones culturales tienen que tener voz, participación. Ellas son parte de la comunidad. La Biblioteca abarca a la comunidad con todas sus organizaciones. Hemos visto que la Biblioteca, cuando logra hacer lazos con las juntas de acción de comunal hay una cosa, una convivencia... Yo recuerdo que en la trece [se refiere a la Comuna 13] venía gente del extranjero, a chismosiar el conflicto armado, y los líderes comunitarios siempre los llevaban a la Biblioteca. Cuando les preguntaban, ¡Ve, ¿qué hay aquí de importante para conocer en la comunidad?...¡Todos caían a la Biblioteca!. Mire, este señor viene de una ONG, de tal parte del mundo... Entonces, uno siente que la Biblioteca sí es un espacio cultural que les ayuda a construir, les ayuda a sentir pertenencia... muchas cosas vitales.

Esta perspectiva se vincula con otra que es la emancipación como objeto de la biblioteca, asunto todavía presente en algunos proyectos bibliotecarios populares. La Biblioteca Binco propone, por ejemplo, que "[la biblioteca debe ser] generadora de conciencia comunitaria" 
Su enfoque es plenamente social con perspectivas de desarrollo transformador de las condiciones de vida de las comunidades y busca ayudar a sus beneficiarios (como nombran a sus usuarios)

[...] a encontrar una nueva visión de su comunidad y una nueva forma de participar en ella desde su perspectiva como individuos pensantes y desde la perspectiva del otro al cual se afecta diariamente.

\section{Función cultural}

Esta función no se revela explícitamente en lo encontrado. De hecho, sólo se encuentran alusiones a la tarea que tiene la biblioteca de difundir un universo simbólico letrado. En primer lugar, en una perspectiva plenamente libresca y canónica, al decir que la biblioteca debe ser “(...) recopiladora, conservadora y difusora de los mejores y más importantes libros de la cultura universal”. En segundo lugar, en una perspectiva en la cual la biblioteca debe “(...) irradiar en la población conductas culturales, que le permiten a la comunidad un desarrollo armónico e integral". O ya un enfoque centrado en la concepción de la lectura como placer y el leer como acción social con alto valor simbólico:

para la biblioteca moderna es prioritario formar lectores y desarrollar actividades encaminadas a descubrir no sólo el placer de leer, sino el valor y la utilidad de la lectura.

\section{Función educativa}

Ésta se propone en dos perspectivas:

- La primera asume a la biblioteca como una institución dirigida a apoyar o complementar a la escuela en su tarea de formadora de lectores. Lo dice una promotora de Comfenalco:

La biblioteca pública debe buscar generar procesos de aprendizaje con otras organizaciones sociales, la escuela por ejemplo. Además, buscar apoyar a la educación básica.

- La otra ve a la biblioteca como institución en sí misma educadora con la tarea de apoyar la educación permanente y con una perspectiva de educación social. La educación es eje fundamental “[...] se requiere una educación liberadora y trascender a una educación para la vida[...]”. 
En otra dimensión interpretativa de esta función, debe decirse que llama la atención la persistencia de una notable (y vieja, por lo demás...) dicotomía entre biblioteca y aula. Unas veces para separarse de ella en términos de una nueva práctica formativa de lectores, que propone que la promoción de la lectura impulsada por la biblioteca debe ser diferente (por renovadora o por placentera...) a la promoción de la lectura impulsada por la escuela. Como lo propone la Fundación Ratón de Biblioteca, al decir que su Centro de Lectura “(...) permite una alegría cultural donde no se concibe la obligatoriedad de las instituciones educativas (...)" Otras, para separarla por las vías de asignarle un supuesto lugar complementario en los esfuerzos de la escuela en la formación vital de los lectores, como lo dice la Biblioteca Pública Piloto:

[la biblioteca] es continuadora perpetua del esfuerzo educativo académico del individuo. $Y$ cuando el individuo llega al final de todos sus posibles estudios académicos, siempre estará la Biblioteca abierta para sus nuevas inquietudes.

Otras ven una separación funcional en la formación del lector que reactualiza la pugna entre lectura y alfabetización, al separar la enseñanza de la lectura del incentivo o permanencia en ella como dimensión cultural fundamental de la cultura moderna, como por ejemplo, la bibliotecaria de una de las bibliotecas públicas populares que dice que

si en la escuela no se le enseña al niño a leer, ¿dónde más? en la biblioteca no... En la biblioteca no hay tiempo para hacer eso, sólo para inducirlo a que lea, a través de los programas que tiene.

\section{Función política}

La concepción de la política como el ámbito de poder desde el cual el sistema genera, irradia y mantiene un cierto orden social, se hace muy clara en el ideal moderno de la biblioteca como ámbito de representación, de clasificación y control. En este sentido, puede decirse que la biblioteca pública es una institución moderna que se idea para albergar a los ciudadanos y ayudar a su plena integración a un orden de mundo. ${ }^{27}$ Toda esta idea se vuelve clara al observar lo que las instituciones y los promotores dicen de la biblioteca y su función política, prácticamente orientada siempre al fomento de una sociedad modern epistemology for library sciencie”, en Library Trends, Vol. 46, Núm. 4 (1998). 
moderna, de corte liberal democrático, promotora de la individualidad y que apunta a la acción comunicativa racional:

Dicen los bibliotecólogos del Departamento de Bibliotecas de Comfenalco, de la mano de Iraset Páez Urdaneta, que la biblioteca debe trabajar en una triple estrategia en la que la ciudadanización sea uno de los ejes, esto es,

(...) la formación de ciudadanos modernos, lo que significa facilitar el acceso de la gente a los ambientes informacionales que adecuadamente incentiven la adquisición de las conductas deseables en un individuo más epistemo-inteligente, tecno-sensitivo, socializador y culturalmente feliz.

La Biblioteca Pública Piloto, por su parte, llama a las bibliotecas públicas "núcleos de desarrollo ciudadano", en una perspectiva de integración y fortalecimiento de la convivencia comunitaria.

Tal vez haya todavía en la expresión de las bibliotecas populares de Medellín, parte de la muy interesante tradición que las gestó en la ciudad por allá en la década de los años 80, es decir, aquella pretensión eminentemente política de apoyar los procesos de organización de la comunidad alrededor de la acción social reivindicatoria y de la promoción social propia de la educación popular. Esos rasgos especiales, y a veces distantes de las bibliotecas estatales o privadas, pueden verse aún en las pretensiones de trabajo comunitario de la Biblioteca La Esperanza o la Biblioteca Binco, que propone en su misión que es su deber brindarles “(...) a los usuarios de BINCO las herramientas necesarias para proyectarse dentro de la comunidad y entender sus medios de participación activa dentro de ella.”

En este escenario son frecuentes las alusiones a la necesidad de que la biblioteca pública contribuye a la expansión de un cierto estado social ideal de vida en democracia. Así, la biblioteca, en palabras de una promotora de Comfenalco, "es por excelencia el espacio de democratización, de acceso al conocimiento por medio de la lectura”. Lo que nos queda por entender es cómo se dan esos procesos de democratización desde la biblioteca, al entender que ésta comporta, (según la teoría política) al menos las siguientes cuestiones: el incremento en la magnitud y equidad de la participación política, la consulta obligada de la población en asuntos como el personal, los recursos y los lineamientos estatales; y la protección de esa población contra acciones arbitrarias del gobierno. $^{28}$

28 Comentarios a la obra de Charles Tilly, en: Mary Luz Aguirre Pugarín, De dónde vienen los derechos. Medellín: IEP, Maestría en Ciencia Política, Informe del Curso Cultura Política, 2006, h. 5 . 
En cuanto a la naturaleza del concepto de lectura, podemos identificar ideas recurrentes que la definen así:

- La lectura como proceso, esto es, como un conjunto de acciones que buscan incorporar al sujeto en un acumulado de saber cultural simbólico, mítico y ritual. Este sujeto hereda un mundo de la vida (un acervo de conocimientos culturales) y lo recrea desde sus acciones en la vida cotidiana. Igualmente, otros definen a la lectura como proceso en el que interactúan varios aspectos: el lector, el texto y el autor mediados por un contexto que los rodea y determina. Finalmente, encontramos una alusión a la lectura como proceso de integración de las personas al mundo social, por la acción socializadora que ésta cumple. Esta última idea permite afirmar que la lectura es una dimensión que pone en relación al hombre con el mundo y consigo mismo para hacerle frente a las exigencias de la vida en comunidad. En este sentido, la lectura se asume como una interpretación del mundo.

- La lectura como producto, es decir, la lectura es vista como el resultado de acciones tales como pasar los ojos por las líneas de un texto. Además vale la pena señalar que en otros casos no es la lectura vista como producto, es la comprensión el producto deseado y esperado de la lectura como proceso, en una clara alusión a perspectivas de corte psicolingüístico comprensivista.

- La lectura como experiencia, para este caso, calificada de formativa y gozosa. En primer lugar, la experiencia de la lectura como formativa pone en evidencia la relación entre sujetos, procesos y contextos de enseñanza y aprendizaje mediados por la lectura. Sin embargo, la experiencia solo podría ser calificada como tal en la medida en que haya tenido lugar en el sujeto lector un acontecimiento significativo y transformador: esto quiere decir que la experiencia lo será en tanto haya sido vivida y padecida por un sujeto lector, no simulada y controlada. En este sentido se puede afirmar que la lectura como experiencia sólo tiene lugar en tanto el lector haya vivido realmente el acontecimiento de la lectura. En segundo lugar, la experiencia de la lectura como gozosa podría aludir a que sólo en la medida en que la lectura genere placer podrá ser calificada como experiencia, como acontecimiento con sentido en el sujeto lector. Si la lectura no produce placer, no tendrá lugar entonces la experiencia de la lectura. Estas ideas se han difundido con mucho éxito en el campo de la promoción de la lectura y se han convertido en un imperativo categórico de sus iniciativas. 
- La lectura como ejercicio, en un caso concreto se alude a la lectura desde este aspecto con énfasis en lo político. El ejercicio se refiere a la acción de ejercitar o ejercitarse, a la acción o el efecto de ejercer. En esta medida, la lectura como ejercicio político involucra la acción de un sujeto que busca hacerse visible en el espacio político para recuperar su voz y su palabra.

- La lectura como instrumento o herramienta, esto es, como un artefacto cultural que le permite al sujeto enfrentarse a las adversidades de la vida cotidiana con cierta familiaridad y desde cierta comprensión formal y natural del mundo. Las herramientas y los instrumentos sirven para algo o nos servimos de ellos para realizar algo, así pues, la lectura como herramienta, sirve, por ejemplo, para "el desarrollo de las capacidades humanas", "desenvolvernos en el mundo", "integrarnos a un cultura democrática", "ejercer el derecho a la educación", entre muchas otras finalidades.

- La lectura como habilidad, esto es, como capacidad y disposición para hacer algo. Asimismo se define a la lectura como el dominio de un conjunto de destrezas para desenvolverse, en general, en la vida social y, en particular, en el mundo educativo.

- La lectura como "la forma más refinada de cultivar nuestro lenguaje", esto es, como la forma más aceptada y legitima para adquirir y acumular un amplio capital lingüístico, pues como lo dice la Biblioteca Comfama: "un lenguaje pobre nos deja indefensos, sin la posibilidad de participar y ausentes de las decisiones sociales, culturales y políticas, definitivas para vivir en comunidad".

En esta misma línea situamos la expresión de una de las bibliotecas públicas participantes referida al concepto de lectura como "un acto sagrado", es decir, a la lectura como un ritual revestido de orden, control y normalización, lo que reafirma la existencia de cánones inviolables y de instituciones que velen por el cumplimiento de estos preceptos que permiten y estimulan - mediante el control— ciertos tipos deseables de relaciones del lector con el texto.

En general puede decirse que el concepto de lectura es definido usando comprensiones que van desde perspectivas complejas e integradoras, hasta aquellas que la reducen al acto de "seguir con los ojos las líneas de un texto". Llama la atención que aún se hable de la lectura desde enfoques tan tradicionales e incluso cuestionados. Esto podría indicar la necesidad de impulsar procesos de formación y reflexión sobre la promoción de la lectura en las instituciones bibliotecarias que la promueven. 
En lo que tiene que ver con los enfoques predominantes en el concepto de lectura, identificamos, en principio, un enfoque eminentemente canónico ${ }^{29}$ de la lectura como aquello que valora, en exceso, la importancia de favorecer un encuentro del lector con lo que es considerado digno de leer. Un ejemplo de ello es la siguiente idea de un promotor de la lectura:

una buena selección de autores, su lectura cuidadosa, su meditación, el respeto y la valoración por las ideas expresadas, es la fragua que inevitablemente forjará el pensamiento y al pensador sensato.

En este enfoque, la lectura debe estar regida por cánones literarios que pretenden asegurar y garantizar un acercamiento civilizador del lector con obras estéticamente valoradas. Sin duda en ellos se plantea una relación estrecha entre la cognición, el acto de construcción y apropiación del sentido del texto, y el placer que podrá experimentar el lector. Solo habrá placer en la medida en que el lector haya logrado construir y apropiarse del sentido del texto, como bien lo ilustra esta otra idea de un promotor de la lectura:

toda lectura bien hecha nos deja sembrados múltiples interrogantes y fortalece irremediablemente el pensamiento. Cada palabra viva y pertinente puede suscitar una pregunta, provocar evocación; desatar múltiples imágenes que, finalmente, se convierten en ejercicio necesario para forjar el pensamiento.

A este enfoque canónico, como hemos optado por calificarlo, se adhieren otras alusiones asociadas al placer y al goce que produce la lectura: "la lectura es un momento divertido" (Biblioteca Pública del sector privado). Un goce que se experimenta por fuera de las posibilidades proscritas, al parecer, por otros espacios sociales; la escuela, por ejemplo. El placer se aleja de las aulas, pero se refugia en la privacidad, en la soledad del lector que se escapa de la materialidad del mundo y se instala en las difusas fronteras de la imaginación y la ensoñación; "leer es otra manera de volar" (Biblioteca Pública del sector privado). Este enfoque podríamos denominarlo funcionalista intimista, pues privilegia una relación muy solitaria y privada del lector con el texto.

No obstante, identificamos otro enfoque mucho más centrado en una idea de la lectura ligada a la relación, a la conversación, al encuentro, a la socialización de los sujetos. Una lectura puesta en el proceso de construcción de lo humano, de la elaboración permanente de un proyecto colectivo en el que tiene son etiquetadas de imprescindibles en la experiencia de lectura de un lector culto. 
presencia el sujeto en todas sus dimensiones: afectiva, emotiva, biológica, cognitiva, comunicativa, valorativa, ética, lúdica, estética, política y cultural. A este enfoque podríamos denominarlo desarrollista de corte socializador pues le atribuye a la lectura un lugar central en los procesos de integración del sujeto a las estructuras sociales, a un mundo de la vida que lo recibe y lo acoge. Por lo tanto leer se vuelve una práctica de sociabilidad (es decir, el conjunto de actividades simbólicas que le permiten al sujeto socializarse).

Por último, nos referimos a las finalidades atribuidas a la lectura. En ello queremos resaltar la presencia recurrente de dos ámbitos: el personal y el social. De un lado, la finalidad de la lectura suscrita al campo de desarrollo individual, el cual se refiere a que la lectura les permite a los sujetos adquirir conocimientos y destrezas, y desarrollar habilidades de pensamiento y de comunicación:

acceder a información cifrada y usarla, comunicarse, elaborar conocimientos, interpretar, seguir instrucciones, recrearse, ampliar sus horizontes mentales y confrontarse culturalmente (Biblioteca Pública del sector privado).

Por otro lado la lectura suscrita al desarrollo social y económico de las comunidades, pues en la medida en que el lector adquiere la habilidad de leer podrá desenvolverse con mayor soltura en el medio social y laboral y contribuir al mejoramiento de las condiciones de vida personal y social. No es gratuita y menor la alusión permanente a la lectura como aquello que "permite el desarrollo social y comunitario".

En general en este enfoque se depositan en la lectura esperanzas de ampliación de la participación, y de avances en el desarrollo social y en el crecimiento económico. Adicionalmente, queremos resaltar una alusión a la lectura como aquello que "realiza al lector como ciudadano" (Biblioteca Pública del sector estatal). En este sentido, la lectura es la que permite la formación y la expresión del sujeto como ciudadano, como sujeto con presencia pública y con identidad política. La lectura así se constata como una dimensión simbólica desde la cual es posible enunciar el mundo, por ejemplo, en su espacio político.

\section{LAS REPRESENTACIONES BIBLIOTECARIAS DEL LECTOR}

Respecto del concepto de lector hay una convergencia notable en considerarlo como sujeto individual y no como sujeto colectivo. Esto es, las bibliotecas no aluden a comunidades, segmentos o capas lectoras. No obstante, hay implicaciones colectivas y sociales que se desprenden de las características señaladas 
en casi todas las definiciones de lector como un sujeto que debe estar en capacidad o tener la actitud, de querer transformar su entorno y su realidad. Llama también la atención la existencia de conceptos muy elaborados sobre el lector en los sistemas bibliotecarios o bibliotecas con mayor tradición en el campo de la promoción de la lectura (que se perciben como producto de una larga reflexión), y que contrastan los otros conceptos realmente precarios sobre el lector, que simplemente lo relacionan con la actividad de leer.

En cuanto a los enfoques dados al concepto de lector se advierten esencialmente dos:

- Uno de corte crítico que le otorga al lector el poder de construir su vida y el mundo social a partir de la práctica de leer.

- Otro, de corte funcionalista intimista, que relaciona al lector con el mundo más desde la emoción y la sensibilidad, en clara alusión a la conformación de la vida íntima. La siguiente idea da cuenta plenamente de este enfoque:

[el lector] es aquel que se pierde en la atmósfera, la interioridad y las imágenes del libro, pero que finalmente se encuentra, solidario o pensativo, en la compañía perdurable del autor. (...) Un buen lector es el que, buscador del saber y admirador del creador, acaricia con cariño un buen libro y lo estrecha entre sus manos o lo guarda en lo profundo del bolsillo temiendo no tanto extraviarlo, como sí perder al amigo potencial y leal que es el escritor.

Tal vez podría ser entendida la ausencia de respuesta sobre el asunto del enfoque en la mayoría de las bibliotecas populares, como una dificultad para comprender al usuario de la biblioteca como lector. Puede decirse al respecto de esta tensión entre las denominaciones usuario y lector que el estatus común de las personas en la biblioteca pública moderna ha sido la de lectores, una representación afincada en la idea, ya comentada, de que las personas construyen sentidos del mundo con lo que leen, y que esos sentidos los integran y les dan lugar en la civilización.

En correspondencia, esta representación bibliotecaria del lector está fuertemente apegada al canon de lectura y al refinamiento estético, cosas en las que la biblioteca pública ha visto una oportunidad para relacionarse y encontrar lugar dentro de los discursos hegemónicos de la cultura y de la educación y, de paso, fundamentar su pretensión de institución para todos. Pero este estatus varió no poco con el advenimiento de las ideas de sistemas de información en los años sesenta y con la imposición de los principios de la bibliotecología 
instrumental y práctica que Unisist y PGI difunden para finales y principios de esa década y de la siguiente. ${ }^{30}$ Ahora las personas ya no son esencialmente lectores para las bibliotecas, sino ante todo usuarios de la información. Bien lo ilustra la siguiente cita en la cual será lector de la biblioteca: "aquel que necesite información y conocimiento, o quiera distracción y buena utilización del tiempo libre por medio de la lectura, sin discriminación alguna”.

A lo sumo en esta perspectiva bibliotecaria, la lectura se reconoce como proceso interpretativo de base dentro de un proceso mayor que es el proceso informativo, de forma que el lector se vuelve una arista apenas visible de la nueva figura de usuario. A esta nueva categoría subyace una gran limitación discursiva bibliotecaria que hace confundir información con lectura, y lector con usuario.

Sin embargo nos encontramos con la aparición de otro enfoque, el desarrollista (de corte psicolingüístico), en el que se le atribuye un lugar especial al lector en el proceso de interacción de éste con el autor y el texto en contextos determinados, resultado de la cual interacción es la construcción de significados y sentidos. Este enfoque se ve plasmado en la siguiente afirmación que dice que lector

es el que realmente le da vida al libro cuando interactúa con él. ¿Cómo interactúa con él? Con los aprendizajes previos o significados confrontándolos para generar nuevos conocimientos y posturas frente a la realidad.

En lo que se refiere a los perfiles de formación que proponen las bibliotecas públicas de la ciudad, nos encontramos con dos asuntos recurrentes:

- El primero alude a la necesidad de formar al lector para el uso de la información desde perspectivas universales, múltiples, críticas y autónomas. Esto sugiere la necesidad de tener un lector lúcido con intereses y capacidades de actuación y proyección en el mundo social. No obstante, sólo hay una mención explícita del lector como persona capaz de producir textos, lo que vincula a la lectura con el universo de la escritura.

- El segundo, desde una cierta preocupación por el uso del tiempo libre, busca formar "lectores lúcido-placenteros”. Esta alusión al lector como un sujeto capaz de producirse placer con la lectura es una consecuencia de los enfoques intimistas muy arraigados en las prácticas de promoción de la lectura.

30 Revísese el muy interesante artículo: Sonia Gironelly Pérez, "Paradigmas y no paradigmas: Una conceptuación necesaria”, en Ciencias de la Información, Vol. 28, Núm.2 (jun. 1997); pp. 75 - 90. 


\section{LAS REPRESENTACIONES BIBLIOTECARIAS}

DE LA PROMOCIÓN DE LA LECTURA

Con el propósito de reconstruir las múltiples definiciones dadas al concepto de promoción de la lectura, a continuación presentamos las ideas recurrentes y divergentes para ilustrar la variedad de opciones, posturas, enfoques, finalidades y posiciones que asumen las personas y las instituciones a la hora de explicar aquello que es objeto de su práctica: la promoción de la lectura. Partimos del supuesto de que lo que hacen las personas y las instituciones está en estrecha relación con lo que dicen; es decir, sus discursos explicativos y comprensivos del fenómeno objeto de su trabajo.

Así pues, debe señalarse en primer lugar, que el concepto de promoción de la lectura está referido a:

\section{- La Promoción de la lectura como acción o conjunto de acciones}

dirigidas a acercar a un individuo o comunidad a la lectura, elevándola a un nivel superior de uso y gusto; de tal forma que sea asumida como una herramienta indispensable en el ejercicio pleno de la condición vital y civil.

Esta es una de las definiciones que goza de mayor prestigio y reconocimiento entre las bibliotecas públicas de la ciudad, data de principios de los años noventa y ha sido difundida por las bibliotecas de la Caja de Compensación Familiar de Comfenalco. A esta definición, en general, se afilian las bibliotecas de la Red Municipal, la Biblioteca Pública Piloto, Biblioteca La Esperanza y la Biblioteca PAN. Asimismo, Comfenalco define a la promoción de la lectura como "una macroacción con la cual un país, una comunidad, una institución o un individuo contribuyen a formar una sociedad lectora".

En este sentido la promoción de la lectura se despliega en dos frentes básicos de trabajo: por un lado las microacciones que buscan acercar a individuos y comunidades a la lectura con el fin de transformar sus prácticas y representaciones desde las acciones que puedan realizar diferentes instituciones sociales, entre ellas la biblioteca pública; y por el otro, las macroacciones, o acciones sinérgicamente articuladas de todas las instituciones sociales que hacen parte del sistema de formación social de los lectores y que confluyen en la pretensión de configurar una sociedad lectora, es decir, una sociedad que valora e integra la lectura en las diferentes dimensiones de la vida íntima, social y política. En estos términos, la promoción de la lectura es una responsabilidad 
no sólo de la biblioteca pública, a ella también se ven abocadas otras instituciones sociales como la familia, la escuela, el Estado y los medios de comunicación, entre otros.

- La Promoción de la lectura como proceso sociocultural apunta a la interacción de múltiples elementos del orden social y cultural con un objetivo común. La promoción de la lectura dinamiza las dimensiones culturales de la lectura y la escritura, dimensiones en las cuales se da la construcción de un horizonte común para las personas, el cual es compartido en el mundo de la vida.

- La Promoción de la lectura como servicio básico inherente al ser (esencia histórica) y quehacer (intervención social) de la biblioteca pública En este sentido la promoción de la lectura es vista como un producto organizacional que busca satisfacer necesidades de información de los usuarios en su condición de lectores. La promoción de la lectura es el puente entre las necesidades de los lectores y su satisfacción, para lo cual los pone en relación con los materiales de lectura que podrán satisfacer esas necesidades de información y formación derivadas de su acción en diferentes esferas de la vida.

- La Promoción de la lectura como una propuesta de intervención social por parte de la Biblioteca pública está en consonancia con el cumplimiento de las demandas sociales que sobre ella hacen el Estado y la sociedad. La intervención se refiere al conjunto de acciones intencionadas que buscan transformar y mejorar condiciones particulares en la vida de las personas y las comunidades. En especifico, la promoción de la lectura como intervención, hace alusión a todas aquellas acciones sociales (planeadas, organizadas, ejecutadas y evaluadas) que emprende la biblioteca pública para transformar las representaciones y las prácticas de las personas y las comunidades con respecto a la lectura y la escritura.

- La Promoción de la lectura como práctica de pedagogía social es entendida como el conjunto de acciones educativas dirigidas a orientar y fortalecer en los sujetos, los aprendizajes sociales y ciudadanos necesarios para integrarse y desenvolverse en la vida social y política. Esta definición reafirma el interés decidido de la biblioteca pública por apoyar los procesos de formación social y ciudadana de los sujetos, los cuales transcurren por fuera de los escenarios formales de las instituciones educativas. Llama la atención la integración que se hace de los procesos de enseñanza y de aprendizaje en la promoción de la lectura, la cual debe ser un proceso que implica pensarse, ejecutarse y 
evaluarse para lograr el objetivo que se propone la formación de lectores autónomos y reflexivos que vayan construyendo una posición en el mundo y sean partícipes de la construcción de ciudadanía como seres con plena conciencia de participación. En todo ello no es gratuito que sea la Fundación Ratón de Biblioteca la más interesada en promover este tipo de comprensiones dado todo el trabajo que ha desplegado en la zona nororiental de la ciudad de Medellín y que ha sido el fruto de aprendizajes y del trabajo coordinado con otras organizaciones de base popular y comunitaria.

- La Promoción de la lectura como arquitectura teórico-conceptual. En ella que se despliegan todas las acciones emprendidas por las bibliotecas en términos de lectura y escritura, esto es, la plataforma comprensiva en la cual se soportan los planes, programas, proyectos y actividades de lectura y escritura en la biblioteca pública. Tal es el caso de la Fundación Ratón de Biblioteca la cual afirma que la promoción de la lectura "es la sustentación filosófico-conceptual".

- La Promoción de la lectura como estrategia; es decir, como procedimiento que busca poner en relación el mundo de los lectores con el mundo de los libros: "que la población en general se acerque a los libros”. La promoción de la lectura es la mediadora entre los lectores y el mundo de la lectura, de los libros que esperan ser redescubiertos permanentemente por nuevos lectores. Otra expresión de esta idea es concebir la promoción de la lectura como estrategia de mercadeo para "promocionar" a la lectura como bien de consumo cultural ampliamente valorado: "[es] hacer dar gusto de... (todo entra por los ojos)". La promoción de la lectura, en estos términos, busca incrementar los consumos culturales de los lectores.

Además, notamos que en pocas de las definiciones se alude a la escritura como parte integral de la promoción de la lectura. La escritura no se hace visible como correlato de la lectura.

En todas estas definiciones identificamos elementos comunes que podrían caracterizar a la promoción de la lectura:

- La promoción de la lectura es una acción o conjunto de acciones sociales intencionadas que buscan generar, acercar, permitir y favorecer una relación de los lectores con las dimensiones culturales de la lectura y la escritura.

- La promoción de la lectura pretende transformar las comprensiones y prácticas de los sujetos y las comunidades con la lectura y la escritura. 
- La promoción de la lectura está ligada a una estructura organizacional e institucional.

- La promoción de la lectura compromete esfuerzos, tiempos y recursos en un horizonte de intervención social en el que participa la biblioteca pública.

- La promoción de la lectura "es el objetivo estratégico de la biblioteca pública”; ${ }^{31}$ es decir, el sentido primigenio y básico de la acción bibliotecaria pública.

En segundo lugar, en las definiciones sobre el concepto de promoción de la lectura identificamos la presencia de varios enfoques, a saber:

- Los enfoques desarrollistas, como hemos optado por llamarlos, le atribuyen a la promoción de la lectura un interés en "formar una sociedad lectora”. Así, la promoción de la lectura pone en juego un conjunto de elementos, estrategias, mecanismos, recursos y ambientes que buscan propiciar un encuentro renovado entre los lectores y la lectura, entre los lectores y los universos simbólicos, entre los lectores y el mundo de la vida. Aquí vale la pena señalar que aunque se le atribuya a la promoción de la lectura un énfasis formativo (hacer de la sociedad una sociedad lectora) ello no es visible salvo en pocos casos en loa que hay una alusión directa a la promoción de la lectura como estrategia de formación y como práctica pedagógica.

- Los enfoques funcionales optan por resaltar la promoción de la lectura como una estrategia que busca superar los déficit culturales, la pobreza externa que profundiza las brechas entre los que "leen" y los que "no leen", entre los lectores y los no lectores, para favorecer su inclusión cultural, pues "el que no lee se afirma que tiene una pobreza externa y la promoción de la lectura debe ayudar a superar ese estado”. En este mismo sentido citamos a uno de los promotores quien afirma que la promoción de la lectura "ayuda a salir de la ignorancia". En esta misma línea ubicamos un enfoque funcionalista de corte canónico que busca promover la lectura de un conjunto de libros etiquetados como imprescindibles en el proceso de formación de un sujeto culto y a la altura de su época. Muestra de ello son algunas citas que a continuación presentamos, las cuales le atribuyen a la promoción de la lectura la tarea de "transmitir a las personas que leer es un placer", extender

31 ENTREVISTA, Gloria María Rodríguez Santamaría [Bibliotecóloga], Entrevista elaborada por Luz Marina Guerra y Yicel Nayrobis Giraldo, Medellín, 22 de mayo de 2007, 45 minutos. 
"el goce del acto de leer", partiendo de la idea de que "la cultura se adquiere a través de los libros”.

- Por último, identificamos los enfoques sociales que pretenden poner en relación a la promoción de la lectura con diferentes esferas del mundo social, en su doble expresión estructural: como mundo de la vida y como sistema. Por un lado se propone la promoción de la lectura con énfasis en el desarrollo bumano y la intervención familiar y, por el otro se la vincula con los procesos de formación ciudadana.

En primer término, el enfoque social con énfasis en el desarrollo humano alienta la idea de que la promoción de la lectura es una estrategia que busca potenciar el desarrollo integral de los seres humanos en sus diferentes dimensiones: cognitivas, psicológicas, emotivas, lúdicas, afectivas, recreativas, biológicas, éticas, estéticas, comunicativas, lingüísticas, sociales, políticas y culturales. La promoción del desarrollo humano parte del supuesto de que es necesario emprender esfuerzos comprensivos y prácticos para generar espacios — sociales e interdisciplinares - y ambientes que le confieran realidad y oportunidad al despliegue integral de lo humano. En ello tiene lugar, obviamente, la promoción de la lectura como aquella estrategia que despliega la biblioteca pública para favorecer el desarrollo humano de las personas y de las comunidades a las que atiende. Sin duda el desarrollo humano le otorga un nuevo lugar al sujeto, y desde estos nuevos lugares se reorientan las acciones que buscan dignificar la presencia del hombre en el mundo. El desarrollo, como lo propone Max-Neef ${ }^{32}$ en su enfoque "desarrollo a escala humana", es de las personas, no de las cosas, en clara oposición a los enfoques del desarrollo centrados en la acumulación de riquezas que van en desmedro de las condiciones de vida digna de la mayoría de la humanidad. En esta línea pueden situarse algunas perspectivas bibliotecarias como por ejemplo las de la Biblioteca de Comfama, que alude a estar "fortaleciendo al ser humano, porque cuando hacemos promoción de la lectura estamos haciendo promoción humana”.

En cuanto al enfoque social con énfasis en la intervención familiar, éste se dirige a mejorar los procesos de promoción de la lectura en el seno de las familias. Esto se refirma en tanto que las bibliotecas públicas han venido incursionando con nuevas propuestas de intervención en la familia; esto es, con programas dirigidos a los primeros lectores y a la primera infancia; programas para madres gestantes y padres y madres de familia, y programas que en general apuntan a una relación más afectiva y emocional con la lectura en los hogares. 
Es así como las bibliotecas públicas enfilan sus esfuerzos en transformar las bases que las familias incorporan en cuanto a la lectura y la escritura. Tal y como lo afirma la Biblioteca La Esperanza, la promoción de la lectura debe "transformar [las] bases que por diferentes circunstancias en la familia se desvían".

En segundo término aparece el enfoque social con énfasis en la formación ciudadana, el cual nos estaría indicando que la promoción de la lectura es una "estrategia [que pretende] cerrar la brecha entre unas ciudadanías diagnosticadas como deficitarias y el ideal de ciudadano cívico y virtuoso que ha estado en el horizonte normativo colombiano, es decir, tanto en la constitución y las leyes, como en los contenidos curriculares de la educación". ${ }^{3}$ Así como lo indica la siguiente cita, la promoción de la lectura es "una propuesta de formación ciudadana relacionada con formar mejores personas, buenas personas". El ideal de formación de ciudadanos está puesto en la formación de personas virtuosas, respetuosas del orden y de las leyes. Estos son los horizontes que orientan muchas de las iniciativas de promoción de la lectura impulsadas por las bibliotecas públicas de la ciudad.

Otro asunto que cautiva nuestra mirada está referido a las fronteras tan difusas y esquivas entre la promoción de la lectura y la animación. En las bibliotecas públicas aún no son lo suficientemente claras las diferencias entre uno y otro concepto. En algunos casos este concepto es asimilado al de animación a la lectura por cuanto se alude a la promoción como el conjunto de estrategias dirigidas a potenciar el uso y disfrute de la lectura por parte de los niños en relación con los libros. Un buen ejemplo de ello es el siguiente testimonio que se refiere a la promoción de la lectura como

el conjunto de acciones encaminadas a permitir el acceso a los libros y a la información, a través de estrategias que propicien el disfrute, comprensión y apreciación del mismo. (...) Es acompañar a los niños en el proceso lector acercándolos a los materiales bibliográficos a partir de la lectura en voz alta, la narración oral, la composición escrita, los juegos literarios, concursos, etc.

En este concepto identificamos la alusión directa a estrategias de animación a la lectura como acciones que se equiparán a la promoción de la lectura. En este trabajo optamos por entender a la promoción de la lectura como

un trabajo de intervención sociocultural que busca impulsar la reflexión, revalorización, transformación y construcción de nuevos sentidos, idearios y prácticas

33 Deicy Patricia Hurtado Galeano y Didier Álvarez Zapata, "La formación ciudadana en contextos conflictivos”, en Estudios Políticos. Medellín, Núm. 29 (jul. - dic. 2006); p. 81. 
lectoras, para así generar cambios en las personas, en sus contextos y en sus interacciones. A partir de ello intenta fortalecer a los lectores como actores sociales, para que sean capaces de afrontar los retos vitales, sociales, culturales, políticos y económicos. ${ }^{34}$

En lo que respecta a las funciones atribuidas a la biblioteca pública en relación con la promoción de la lectura, las más recurrentes son aquellas que tienen que ver con la educación:

- La "educación es el eje fundamental de la biblioteca pública". La promoción de la lectura debe partir de una educación liberadora que transcienda en una educación para la vida.

- La biblioteca pública "debe apoyar a la institución educativa y su Proyecto Educativo Institucional”. Las bibliotecas públicas vienen asumiendo responsabilidades de formación de lectores ante las dificultades que han surgido en los sistemas educativos formales. Esto ha hecho que circulen discursos que buscan colonizar el espacio de la escuela con propuestas desde la biblioteca pública, y la escuela, muy a su manera, busca apropiar e incluso moldear el espacio de la biblioteca pública a sus necesidades. En este juego de ires y venires, los lectores se enfrentan a una variedad de iniciativas y propuestas que no logran establecer con claridad cuál es el lugar de la escuela y de la biblioteca pública en la formación de los lectores. A manera de ejemplo, la siguiente cita ilustra esta situación:

[...] si en la escuela no se le enseña al niño a leer, ¿dónde más? en la biblioteca no. En la biblioteca no hay tiempo para hacer eso, sólo para inducirlo a que lea, a través de los programas que tiene.

Otros elementos conceptuales que aún cuando no aparecen de manera central en los testimonios sí resultan ser muy interesantes para dilucidar la esencia del concepto de promoción de la lectura, son los referidos a las ideas de fomento de la lectura y formación de lectores. En efecto, en la literatura del campo suelen proponerse como sinónimas las ideas de promoción y fomento de la lectura; y también la concepción de la formación de lectores como un problema al que debe vincularse la biblioteca pública. Las inquietudes de la directora de la Biblioteca Pública Piloto, al comentar el desarrollo de la biblioteca pública y la promoción de la lectura en Colombia, ejemplifican con creces el nudo conceptual que encierra: 
[...] hace varios años empezamos a separar las esferas del ejercicio de leer. Hacemos actividades que llamamos de promoción de la lectura, de formación de los lectores y de fomento de la lectura [...] La formación requiere de unas condiciones y de unas metodologías. La formación a la lectura está ligada a la formación a la escritura. [...] Cuando hablamos de la promoción de la lectura la situamos en un lugar lúdico y recreativo [pero] no hacemos un ejercicio mental real [aludiendo a la necesidad de profundizar en sus contenidos sociales y metodológicos]. [El fomento de la lectura] es propiciar unos insumos para la lectura, es hacer encuentro a través de la lectura. Es cultivar algo alrededor de la lectura. ${ }^{35}$

No obstante, aunque no contamos con amplias y arraigadas tradiciones que impulsen un movimiento progresista de reflexión en el campo de la promoción de la lectura, de lo que sí estamos seguros es de que las comunidades han acogido en su cotidianidad propuestas e iniciativas de promoción de la lectura que animan nuevos acercamientos de las personas a la lectura en sus múltiples expresiones y posibilidades. Las experiencias de trabajo en esta línea las recogimos en este conmovedor testimonio de la Biblioteca Las Estancias, que muestra la dimensión del trabajo social que han venido realizando las bibliotecas públicas en los diferentes rincones de la ciudad:

Para mucha gente de los barrios que hemos visitado, la imagen de un carro con libros, algo de música y un par de zanqueros ha sido algo difícil de comprender, incluso han pedido que nos vayamos, "que por allá no se pueden vender libros, que la gente no tiene plata” y un instante después cuando logran asimilar que no se les está vendiendo nada y que, por el contrario, se les ofrece la oportunidad de un instante de esparcimiento completamente diferente a lo que están acostumbrados, es tal la acogida que una de las preguntas más frecuentes entre los niños, y alguno que otro adulto es si vamos a visitarlos todos los días, o todos los fines de semana.

\section{LAS REPRESENTACIONES BIBLIOTECARIAS DE LA ANIMACIÓN A LA LECTURA}

A pesar de que se deba reconocer que para la biblioteca pública contemporánea en Medellín resulta central comprometerse con la tarea de promover la lectura, y por tanto realizar actividades encaminadas a descubrir y fomentar

35 ENTrevista, Gloria Inés Palomino, [Comunicadora social. Directora de la Biblioteca Pública Piloto], y Entrevista elaborada por Luz Marina Guerra y Yicel Nayrobis Giraldo, Medellín, 14 de marzo de 2007, 50 minutos. 
el valor social de ella, no se puede afirmar que tenga un discurso claro y estructurado que entienda satisfactoriamente a la animación a la lectura, diferencialmente de la promoción de la lectura.

En efecto, sólo existe la propuesta hecha por la Coordinación de Fomento de la Lectura (que recoge y desarrolla, a su vez, una conceptuación propuesta por Betancur, Álvarez y Yepes en 1994), ${ }^{36}$ la cual diferencia estructuralmente a la promoción de la lectura (macroacción dirigida a formar una sociedad lectora) de la animación a la lectura (acción dirigida a crear un vínculo entre material de lectura y un individuo/grupo). Aunque está también la idea de la Fundación de Ratón de Biblioteca que asume la promoción de la lectura como "la sustentación filosófico-conceptual" y la animación a la lectura como referida “(...) a la didáctica, al uso de herramientas”, no se encuentra que el problema comprensivo que encierra lo conceptual sea un asunto que interese de manera central o preocupe a los bibliotecarios y a los promotores de la ciudad. Por ello, es apenas lógico observar la precariedad conceptual del discurso en este territorio.

De cualquier forma es evidente que el gran conjunto de actividades que despliegan las instituciones en el campo de la animación lectora, como horas del cuento, talleres, lecturas en voz alta, lecturas individuales, etc., obedece a una concepción un tanto vaga de la intervención lectora de la biblioteca pública, centrada en la acción y dirigida a proponer a la lectura desde el placer, más que desde el esfuerzo trasformativo del sujeto. Ello muestra que las instituciones no han reflexionado sistemáticamente respecto del significado (acuerdo social) y sentido (apropiación individual) del placer de leer, así como tampoco sobre lo que es la animación a la lectura como un proceso profundamente vinculado con lo que Monserrat Sarto llama "educación lectora". 37

Explorando hipótesis es posible afirmar que la idea de animación a la lectura en la biblioteca pública de Medellín se mueve entre dos posturas:

- Primera: que la animación a la lectura es un asunto metodológico. Por esta vía, la mirada sobre la animación enfoca en la dimensión instrumental de la acción cultural. Esta hipótesis se puede ver en los siguientes testimonios: "[la animación a la lectura] es cómo se implementan las actividades". "Las actividades de animación son las distintas estrategias

36 Adriana Betancur B., Didier Alvarez Z. y Luis Bernardo Yepes O., Diagnóstico de la promoción de la lectura en las bibliotecas públicas de Medellín y el Valle de Aburrá, Medellín : Universidad de Antioquia, Escuela Interamericana de Bibliotecología, 1994.

37 María Monserrat Sarto, Animación a la Lectura : con nuevas estrategias, Madrid : SM, 1998. p. 9. 
que llevamos a cabo para que la lectura se vuelva un asunto interesante para el beneficiario". Y "[es] cómo hacer que el otro lea”

- Segunda: que la animación a la lectura es un problema de intervención cultural, fundamentalmente atado a fines lúdicos y estéticos. Por esta vía, la animación a la lectura se pone más en el territorio de los sentidos de la acción cultural pero no la alude, en ningún momento, como una práctica sociocultural. Esto se evidencia en algunas de las propuestas de las bibliotecas públicas, al decir que la animación "es transmitir a las personas que leer es un placer", o que animar a la lectura "es motivar, iniciar, es hacer dar ganas de..."

En términos amplios, puede afirmarse que la idea de animación a la lectura está más perfilada desde el horizonte de la práctica que desde la teoría, en lo que respecta al lugar que tiene en la acción bibliotecaria pública en Medellín. Lo que evidencia que:

- Hay demasiado activismo de las instituciones y no se procura el tiempo necesario para ordenar las categorías comprensivas y explicativas de lo que se hace. Esto dificulta que el trabajo bibliotecario se pueda comunicar o que resulte claro y de interés para otras disciplinas.

- Se hayan difundido ciertos cánones que tienden a estandarizar no solo el alcance y sentido de la animación de la lectura en su significado y sentido, sino también lo que respecta a sus metodologías.

- Se enfatice la acción de animación en el libro, en el libro literario y, todavía más, en la literatura infantil y juvenil. Esto se traduce en que la animación lectora se ejerza, prácticamente, sólo con estos públicos. No obstante cabe decir que cada vez más instituciones exploran otras manifestaciones artísticas (el teatro, por ejemplo).

Con todo, es claro que la animación a la lectura en la biblioteca pública en Medellín tiene unos referentes tácitos, comunes y positivos:

- Se la considerada inherente al quehacer cotidiano de la biblioteca pública.

- Se la aprecia como una intervención directa que permite un acercamiento con la comunidad.

- Las bibliotecas saben de los réditos de su realización: reconocimiento, aprecio y valoración por la biblioteca; especialmente cuando se ejerce con poblaciones altamente significativas socialmente como son los niños y los jóvenes. 
- Tiende a reconocer a quién va dirigida: precisa públicos lectores y los diferencia comparativamente.

- Es mínimamente consciente de las diferentes metodologías y estrategias disponibles y de sus posibilidades. Puede comúnmente dar cuenta de procesos básicos de preparación, control y evaluación de las actividades que la desarrollan

\section{Conclusiones}

Es importante resaltar el interés creciente que el estudio de las representaciones ha venido teniendo en algunos sectores de la bibliotecología latinoamericana. Si bien el tema de las relaciones entre la biblioteca pública y la sociedad no es asunto nuevo en la bibliotecología de la región (pues está presente en el discurso bibliotecario desde las ya remotas iniciativas de la Conferencia sobre el Desarrollo de los Servicios de Bibliotecas Públicas en América Latina, realizado en Sao Paulo, Brasil en 1949, hasta el interés más reciente de algunos programas de postgraduación por las relaciones biblioteca y sociedad en países como Argentina, Brasil y México), sí lo es el tema de las representaciones que la sociedad tiene acerca de las bibliotecas y las representaciones que la biblioteca propone, a su vez, sobre cuestiones específicas como el lector, la lectura, la promoción y la animación a la lectura.

En esto hay que advertir que la integración de la bibliotecología a un discurso más amplio de las ciencias sociales y humanas, particularmente al de las representaciones sociales, es una cuestión que está por construirse y que habrá de contribuir a lo que el profesor Héctor Guillermo Alfaro ${ }^{38}$ llama la ruptura epistemológica del campo. Cabe esperar que estudios como el que se acaba de presentar en este artículo contribuyan directamente a promover un estatuto más social de la bibliotecología, empezando por reconocer la manera como discurre sobre la sociedad y sus prácticas en ella, yendo de la preferencia por objetos del orden técnico a la preocupación por asuntos ligados a los procesos de construcción social de la realidad.

Sin duda alguna las representaciones bibliotecarias forman parte de la diversidad discursiva que se produce y circula, implícitamente, en las bibliotecas públicas. Ellas muestran un amplio y rico panorama comprensivo de lo que la biblioteca pública hace con la lectura en la sociedad. Si bien esto es apenas obvio, se hace necesario impulsar la conformación de un campo más

38 Héctor Guillermo Alfaro López, El obstáculo epistemológico y la biblioteca. Ponencia presentada en el v Seminario Hispano Mexicano de Investigación en Bibliotecología y Documentación, México: CUIB, 2008, mimeógrafo. 
ordenado conceptualmente sobre las relaciones que existen entre la biblioteca pública, la sociedad y la lectura.

Esto es evidente en los resultados de la investigación que acaba de presentarse, en los que puede verse como las representaciones que los bibliotecarios tienen de su institución, de las prácticas de la esfera de la cultura escrita y de las dimensiones culturales de la lectura y de la escritura son complejas, pero han sido muy poco sistematizadas e interpretadas. Ciertamente, si bien el lenguaje de los bibliotecarios no es científicamente muy elaborado, sí encierra un rico conjunto de valoraciones y posibilidades comprensivas sobre el mundo social que, normalmente, se pierde o se enmascara detrás del discurso técnico y administrativo. En esto vale recordar la idea del ya citado profesor Alfaro acerca de que la idea tradicional de biblioteca, por su construcción discursiva eminentemente empírica, se convierte en un obstáculo para construir teóricamente un concepto más pleno de ella misma.

Queda entonces un panorama abierto en el que lo más deseable sería que se avanzara con estudios sistemáticos y comparativos que ayuden a dar cuenta en la región, acerca del estado y las perspectivas de la estratégica relación que tiene la biblioteca pública con la dimensión simbólica de la cultura escrita. En esto habrá que abordar, muy juiciosamente, lo que son las prácticas de la promoción de la lectura y lo que con ella se ha querido y se ha podido hacer. La biblioteca pública se debe a los lectores en una doble perspectiva: la de servir como institución de la lectura y como espacio de expresión, y la de promover la ciudadanía. La investigación bibliotecológica en América Latina tiene en este campo un inmenso reto, a la vez que un muy fascinante objeto de estudio.

\section{BibLIOGRAFÍA}

\section{Sociedady discurso}

Barcena, Fernando y Melich, Joan Carles, La educación como acontecimiento ético : Natalidad, narración y hospitalidad, Barcelona : Paidós, 2000, 206 p.

Freire, Paulo, A importancia do ato de ler: Em tres artigos que se completam Paulo Freire. Sao Paulo : COAEZ Editora : Autores editores, 1986, $235 \mathrm{p}$.

Geertz, Clifford, La interpretación de las culturas. Barcelona : Gedisa, 1991, 387 p. 
Giroux, Henry, "Introducción : La alfabetización y la pedagogía de la habilitación política", en Alfabetización : FREIRE, Paulo y MACEDO, Donaldo, Lectura de la palabra y lectura de la realidad, Barcelona: Paidós, 1989.

Mélich, Joan Carles. Antropología simbólica y acción educativa, España : Paidós, 1996, p. 190.

Max-Neef, Manfred, Human scale development. Conception, application and further reflections, Nueva York, Londres : Apex Press, 1991.

Ricoeur, Paul. "El modelo del texto : La acción significativa considerada como un texto", en Del texto a la acción. Ensayos de Hermenéutica II, México: Fondo de Cultura Económica, 2002, 380 p.

Téllez Iregui, Gustavo, Pierre Bourdieu. Conceptos básicos y construcción socioeducativa : Claves para su lectura, Bogotá : Universidad Pedagógica Nacional, 2002, 230 p.

\section{Biblioteca pública}

Alfaro López, Héctor Guillermo, El obstáculo epistemológico y la biblioteca. Ponencia presentada en el v Seminario Hispano Mexicano de Investigación en Bibliotecología y Documentación, México: CUIB, 2008, mimeógrafo.

Álvarez Zapata, Didier y Gómez García, Juan Guillermo, "El discurso bibliotecario público sobre la lectura en América Latina (1950 2000) : Una revisión preliminar con énfasis en Colombia”, en Revista Interamericana de Bibliotecología, Medellín, Vol. 25, Núm. 1 (ene. - jun. 2002); pp. 11 - 36.

COLOMBIA, CONPES. Plan Nacional de Lectura y Bibliotecas. Bogotá: CONPES, 2003.

"Declaración de caracas sobre la biblioteca pública como factor de desarrollo e instrumento de cambio social en América Latina y El Caribe”, 1985, en El Libro en América Latina y el Caribe, Núm. 87 (ene. - jun. 1999); p. 57.

FUNDALECTURA, Inventario de iniciativas de promoción de lectura en Bogotá D.C., Formulario General, p. 1, [documento enviado por correo electrónico].

Greenhalgh, Liz, Worpole, Ken y Landry, Charles, Libraries in a world of cultural change, London: UCL, 1995, 182 p.

International Federation o Library Associations and Institutions, Servicios de bibliotecas públicas: directrices IFLA/UNESCO, Bogotá : FUNDALECTURA, 2002.

Jaramillo, Orlanda y Montoya, Mónica, "Revisión del concepto de biblioteca pública”, en Revista Interamericana de Bibliotecología, Vol. 23, Núm. 1 - 2 (ene. - dic. 2000); pp. 13 - 56 
La Promoción de la Lectura en Medellín y su Área Metropolitana : algo en serio muy en broma, Adriana Betancur, Didier Alvarez, Luis Bernardo Yepes, Medellín : Comfenalco, 2005, 42 p., (Colección Biblioteca Pública Vital).

Medellín, Alcaldía. Secretaría de Cultura Ciudadana, Diagnóstico Rápido Participativo sobre lectura, escritura e información zonal, Conclusiones y recomendaciones, Medellín : Alcaldía de Medellín, 2006, 7 h.

Rodríguez Santamaría, Gloria María, Perspectivas de la biblioteca pública en América Latina, Conferencia, en Cátedra Pública Biblioteca y Sociedad. EIB, UDEA, 5 de junio de 2007. Medellín

UNESCO, Manifiesto sobre la biblioteca pública 1949, [documento electrónico], disponible en: <http://www.fundaciongsr.es/documentos/manifiestos/mani49.htm $>$, [consultado: 28 de abril de 2008].

UNESCO, Manifiesto sobre la biblioteca pública 1972, [documento electrónico], disponible en: http://www.fundaciongsr.es/documentos/manifiestos/mani72.htm, [consultado: 28 de abril de 2008].

UNESCO, Manifiesto sobre la biblioteca pública 1994 [documento electrónico], disponible en: http://www.fundaciongsr.es/documentos/manifiestos/mani94es.htm , [consultado: 28 de abril de 2008].

Universidad de Antioquia. Escuela Interamericana de Bibliotecología (Autor Corporativo. Biblioteca Pública Piloto de Medellin para America Latina, Plan Maestro para los servicios bibliotecarios públicos de Medellín, Medellín, BPP, 2004, p.12.

\section{La lectura y la escritura como fenómenos socioculturales}

Martín Barbero, Jesús, Des-centramiento del libro y estallido de la lectura, en Congreso Nacional de Lectura: Lectura y Nuevas Tecnologías (3. : 1997 : Bogotá). Ponencia del III Congreso Nacional de Lectura, Bogotá : 1997, pp. 155-157.

Montes, Graciela, "Espacio social de la lectura", en De Antología. Asolectura, Núm. 2. (2003); 24-28.

Peña Borrero, Luis Bernardo, “Saber leer otros lenguajes”, en Alegría de Enseñar, Bogotá. Núm.. 40. (jul. - sep. 1999); pp. 12-20.

Petit, Michele, "Lectura literaria y construcción del sí mismo", en Lecturas: Del espacio intimo al espacio público, México : Fondo de Cultura Económica, 2001, pp. 41-59.

Sarlo, Beatriz, "Del plano a la esfera: libros e hipertextos", en Martín Barbero, Jesús y López De La Roche, Fabio, Cultura, medios y sociedad, Bogotá, CES : Universidad Nacional de Colombia, Sede Bogotá, 1997, pp. 65-76. 
Sartori, Giovanni, Homo videns : la sociedad teledirigida, Madrid : Taurus, 1998, pp. 18-53.

\section{La lectura y la escritura como fenómenos sociopoliticos}

Alvarez Zapata, Didier, "De la lectura y la escritura y sus relaciones con la política: Algunas perspectivas de comprensión desde los lenguajes políticos", en Seminario Internacional La Lectura: Pasado Presente y Futuro : Memorias, $\left(1^{\circ}\right.$ : 2003 : México, D.F. $)$

Castrillón Zapata, Silvia, "Lectura, educación y democracia”, en Capitulo Aparte: Revista de la Campaña Nacional Eugenio Espejo por el Libro y la Lectura, Quito. Núm. 1 (abr. 2002); pp. 80-89.

Leme Brito, Luis Percival, "Leitura e política", en Leitura: teoría E práctica, Campinas, Vol. 18, Núm. 33. (jun. 1999); pp. 3-10.

\section{Promoción de la lectura}

Álvarez Zapata, Didier, "Propuesta para el desarrollo de un programa de formación en promoción de la lectura en las escuelas de bibliotecología”, en Investigación Bibliotecológica, México. Vol. 15, núm. 30 (2001):pp. 35-47.

Betancur Betancur, Adriana María y Yepes Osorio, Luis Bernardo, Diagnóstico de la promoción de la lectura en Medellín y el Valle de Aburrá, 1994.

, y Naranjo, Edilma, La animación a la lectura : Manual de acción y reflexión, Medellín : Universidad de Antioquia, Escuela Interamericana de Bibliotecología, 2003, 58 p. (Bibliotecología y Lectura : núm.1)

Chubarian, O., Bibliotecología general, La Habana : Científico Técnica, 1976, 367 p.

ENTRevista, Gloria Inés Palomino. [Comunicadora social. Directora de la Biblioteca Pública Piloto], Entrevista elaborada por Luz Marina Guerra y Yicel Nayrobis Giraldo, Medellín, 14 de marzo de 2007, 50 minutos.

ENTREVISTA, Gloria María Rodríguez Santamaría, [Bibliotecóloga], Entrevista elaborada por Luz Marina Guerra y Yicel Nayrobis Giraldo, Medellín, 22 de mayo de 2007, 45 minutos.

ENTREVISTA, Ana Judith Grajales [Bibliotecóloga. Coordinadora Convenio Interadministrativo Universidad de Antioquia - Municipio de Medellín, Secretaría de Cultura Ciudadana], Entrevista elaborada por Didier Álvarez Zapata y Yicel Nayrobis Giraldo, Medellín, 9 de abril de 2007, 30 minutos. 
ENTREVISTA, Luis Bernardo Yepes [Bibliotecólogo. Coordinador Fomento de la Lectura. Comfenalco Antioquia], Entrevista elaborada por Luz Marina Guerra y Yicel Nayrobis Giraldo, Medellín, 27 de febrero de 2007, 70 minutos.

Ghiso, Alfredo, "Otras lecturas sobre lectores y bibliotecas", en De Antología Núm. 4, Bogotá: Asociación Colombiana de Lectura y Escritura, 2005; pp. 51-58.

Sarto, María Monserrat, Animación a la Lectura : con nuevas estrategias, Madrid : SM, 1998, 219 p.

Shera, Jesse, Los fundamentos de educación bibliotecológica,. México : UNAM, CUIB, 1990, $511 \mathrm{p}$.

\section{Representaciones sociales}

Alexandre, Marcos, Representação social: uma genealogia do conceito, [documento electrónico], disponible en: <http://www.facha.edu.br/publicacoes/comum/comum23/Artigo7.pdf>, [consultado: 14 de julio de 2008].

Araya Umaña, Sandra, Las representaciones sociales: ejes teóricos para su discusión, Costa Rica: FLACSO, 2002, 84 p., [documento electrónico], disponible en: <http://www.flacso.or.cr/fileadmin/documentos/FLACSO/Cuaderno127.pdf>, [consultado: 26 de junio de 2008].

Banchs, María A., Agudo Guevara, Álvaro y Astorga, Lislie, Imaginarios, representaciones y memoria social, en Arruda, Ángela y De Alba, Martha, coords., Espacios imaginarios y representaciones sociales. Aportes desde Latinoamérica, Barcelona: Anthropos, México: UAm Iztapalapa, División Ciencias Sociales y Humanidades, 2007; pp. 47-95.

"Aproximaciones procesuales y estructurales al estudio de las representaciones sociales", en Papers on social representations, Vol. 9, (2000); p. 3.1 - 3.15, [documento electrónico], disponible en: <http://www.psr.jku.at/PSR2000/9_3Banch.pdf>, [consultado: 26 de junio de 2008]

Berger, Peter L. y Luckmann, Thomas, La construcción social de la realidad, Argentina: Amorrortu, 2001, 239 p.

Castorina, José Antonio, Barreiro, Alicia y Toscano, Ana Gracia, “Dos versiones del sentido común: las teorías implícitas y las representaciones sociales", en Castorina, José Antonio, comp., Construcción conceptual y representaciones sociales. El conocimiento de la sociedad, 2 ed. Buenos Aires: Miño y Dávila, 2007, pp. 205-238.

, Clemente, Fernando y Barreiro, Alicia, "El conocimiento de los niños sobre la sociedad según el constructivismo y la teoría de las representaciones sociales”, en Castorina, José Antonio, comp., Construcción conceptual y representaciones sociales. El conocimiento de la sociedad, 2 ed. Buenos Aires: Miño y Dávila, 2007, pp. 177-203. 
Barreiro, Alicia y Clemente, Fernando, "La impronta del pensamiento piagetano en la teoría de las representaciones sociales", en Revista IRICE, Rosario, Argentina, Núm. 18 (Sep. 2004); p. 5-30.

Farr, Robert M., "Las representaciones sociales”, en Moscovici, Serge, Psicología social. Pensamiento y vida social II, Barcelona: Paidós, 1988, pp. 495-506.

Jodelet, Denise, "La representación social: fenómenos, concepto y teoría”, en Moscovici, Serge, Psicología social. Pensamiento y vida social II, Barcelona: Paidós, 1988. pp. 469-494.

Jovchelovitch, Sandra, Psicologia social, saber, comunidade e cultura, [documento electrónico], disponible en: <http://www.scielo.br/ pdf/psoc/v16n2/a04v16n2.pdf > , [consultado: 14 de julio de 2008].

Moscovici, Serge, Psicología social. Pensamiento y vida social II, Barcelona: Paidós, 1988.

Prado De Souza, C., Representaciones sociales y el imaginario de la escuela, en Arruda, Ángela y De Alba, M. coords., Espacios imaginarios y representaciones sociales. Aportes desde Latinoamérica, Barcelona: Anthropos; México: UAM Iztapalapa, División Ciencias Sociales y Humanidades, 2007; pp. 199-231. 